\title{
ASTRONOMIA NA ESCOLA E NO OBSERVATORIO ASTRONÔMICO OS CONTEXTOS EDUCACIONAIS APLICADOS À EDUCAÇÃO EM ASTRONOMIA *
}

\author{
ASTRONOMY IN SCHOOL AND THE ASTRONOMIC OBSERVATORY: EDUCATIONAL \\ CONTEXTS APPLIED TO EDUCATION IN ASTRONOMY
}

\author{
Fernando Roberto da Costa Linhares \\ Mestre em Educação - UFMG | Brasil \\ E-mail: omset@ig.com.br
}

Silvania Sousa do Nascimento

Doutora em Educação - UFMG | Brasil E-mail: silnascimento@ufmg.br

\begin{abstract}
REVISTA PEDAGÓGICA
Revista do Programa de Pós-graduação em Educação da Unochapecó | ISSN 1984-1566 Universidade Comunitária da Região de Chapecó | Chapecó-SC, Brasil
\end{abstract} Como referenciar este artigo: LINHARES, F. R. C. NASCIMENTO, S. S. Astronomia na escola e no observatório astronômico: os contextos educacionais aplicados à educação em Astronomia. Revista Pedagógica, Chapecó, v.15, n.31, p. 129-148, jul./dez. 2013.

RESUMO: O presente artigo é derivado da síntese de uma dissertação de mestrado, na qual discutiu-se a relação que existe entre os conceitos de educação formal, não-formal e informal com os conceitos de ensino, divulgação e popularização em um contexto de educação em Astronomia. Foi investigado objetivos de um grupo de professores que realizam visitas escolares regulares a um observatório astronômico identificados pelo perfil traçado por meio de registro de cerca de 27 mil fichas de visitantes. Dessa maneira, foi possível entender como ambientes, considerados de educação não-formal, são utilizados por professores, e assim verificar a validade da classificação dos contextos educacionais e dos espaços educacionais, de acordo com os processos educativos que ocorrem nesses locais. PALAVRAS-CHAVE: Educação em astronomia. Educação não-formal. Divulgação cientifica. Visitas escolares.
ABSTRACT: This article is derived from a Master Science dissertation which we discuss the relationship between the concepts of formal, non-formal and informal education with the concepts of teaching, dissemination and science popularization in astronomy education context. We investigate teacher's goals that perform regular school visits to an astronomical observatory. The teachers were identified by the profiled registration of about 27,000 records of visitors. Thus it was possible to understand how environments considered non-formal education are used by teachers, and thus verify the validity of the classification of educational context and educational areas, according to the educational processes that occur in these places.

KEYWORDS: Astronomy education. Non-formal education. Scientific popularization. School visits. 


\footnotetext{
* Este artigo é fruto de dissertação de mestrado intitulada 'O objetivo das visitas escolares a um observatório astronômico na visão dos professores', concluída em agosto de 2011, pelo Programa de Pós-graduação da Faculdade de Educação da Universidade Federal de Minas Gerais (FAE/UFMG), elaborada pelo autor, sob a orientação da professora doutora Silvania Sousa do Nascimento.
}

\section{APRESENTAÇÃO}

Este artigo aborda uma discussão que nasce a partir da classificação utilizada por pesquisadores em educação para tentar explicar processos educativos que ocorrem em diferentes espaços: educação formal, não-formal e informal. Será que a educação formal só acontece na escola? E a educação não-formal? Poderia ela ocorrer dentro dos limites escolares ou esta denominação é restrita a processos educativos que ocorrem fora da escola?

Para responder a estas perguntas, nos basearemos em uma dissertação de mestrado intitulada 'O objetivo das visitas escolares a um observatório astronômico na visão dos professores', concluída em agosto de 2011, pelo Programa de Pós-Graduação em Educação da Faculdade de Educação da Universidade Federal de Minas Gerais (UFMG). Esta pesquisa procurou investigar os objetivos de professores que regularmente realizam visitas escolares a um observatório astronômico, local considerado pelos professores como sendo um espaço não-formal de educação em Astronomia.

Partimos, inicialmente, de três temas que julgamos essenciais à inserção deste estudo no campo da pesquisa em educação: educação não-formal, divulgação científica e visitas escolares. São temas distintos, mas que possuem uma íntima relação entre si. Em seguida, discorremos sobre um quarto tema, também essencial, que constitui a área específica a que se refere a investigação: a educação em Astronomia. Ao relacionar este tema com os três primeiros, originamos distintos contextos educacionais para a Astronomia, através do seu ensino nas escolas, sua divulgação nos espaços não-formais, como observatórios astronômicos e planetários, ou ainda a sua popularização através dos diferentes meios de comunicação. Dessa forma, atingimos o objeto desta pesquisa, que são as visitas escolares ocorrentes em um espaço não escolar de Astronomia, o observatório astronômico, um ambiente no qual se realizam observações astronômicas com diferentes finalidades: pesquisa, estudo, ensino, divulgação, popularização ou apenas contemplação.

A figura 1 mostra, de forma esquemática, os principais temas que serão abordados no artigo, sendo que os quatro primeiros são aqueles que compõem a base da nossa discussão, os quais serão detalhados a seguir. 


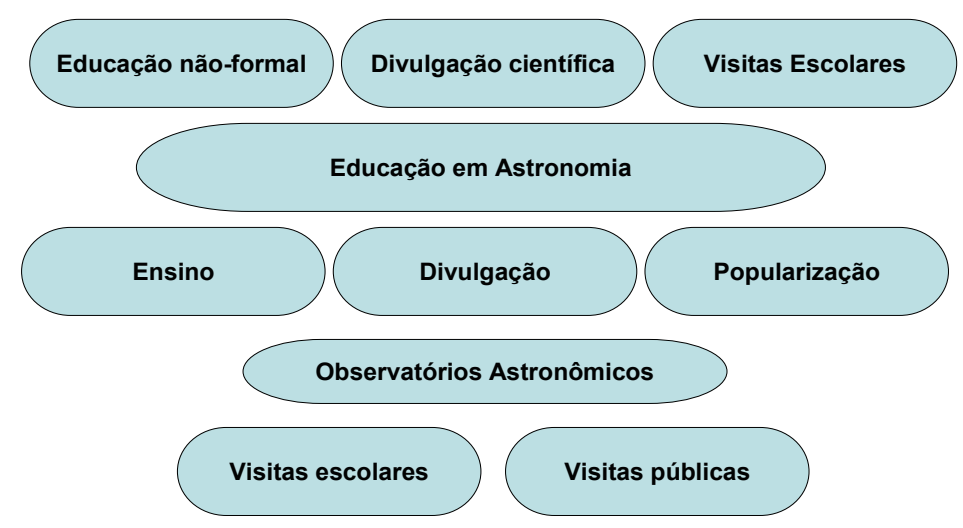

Figura 1 - Referenciais teóricos da pesquisa

\section{EDUCAÇÃO NÃO-FORMAL}

A discussão sobre educação não se restringe apenas ao âmbito do ensino formal, visto que as escolas não alcançam contemplar todo o conhecimento humano. Os currículos e programas disciplinares são extensos e limitados, de modo que não há nem espaço nem tempo para que a escola acompanhe a evolução da ciência em sala de aula. Dessa forma, tem aumentado, cada vez mais, as funções e os usos dos espaços de educação extra escolares, que vêm oferecendo, de forma complementar, o que as escolas não podem assegurar no tempo escolar.

Hoje em dia, é comum que, além da sala de aula, os professores utilizem outros espaços para ensinar. O processo educativo é composto por processos de socialização que acontecem em ambientes de diálogo, de visitas, em contextos de intervenções, e nas experiências práticas do cotidiano. Assim, denominações como educação formal, não-formal e informal passaram a ser utilizadas por pesquisadores em educação para tentar explicar processos educativos que ocorrem em diferentes espaços.

Analisando estudos sobre esse contexto, verificou-se não existir consenso para a definição do termo 'educação não-formal'. Como indica Cazelli (2000), os autores de língua inglesa utilizam os termos 'formal' e 'informal' para designar os tipos de educação em diferentes ambientes, sendo formal a educação que acontece dentro da escola e, informal, aquela que ultrapassa os muros escolares. Já os de língua portuguesa acrescentaram uma terceira denominação, o termo 'educação não-formal', como sendo aquela restrita a museus, centros de ciências e cursos que ocorrem além da sala de aula. Neste caso, o termo 'educação informal' passa a descrever aquela relativa a ambientes cotidianos familiares, de trabalho ou de lazer.

Marandino (2008) apresenta um breve histórico sobre a definição de educação não-formal, situando o uso dessa expressão em políticas educacionais a partir dos anos 
1960. Desde então, surgiram tentativas para definir e categorizar os diferentes contextos educacionais de aprendizagem. Uma delas, bastante aceita inclusive por pesquisadores e educadores brasileiros, é aquela proposta por Combs, Prosser \& Ahmed, em 1973, conforme apresenta Marandino (2008):

- educação formal: sistema de educação hierarquicamente estruturado e cronologicamente graduado, da escola primária à universidade, incluindo os estudos acadêmicos e as variedades de programas especializados e de instituições de treinamento técnico e profissional.

- educação não-formal: qualquer atividade organizada fora do sistema formal de educação, operando separadamente ou como parte de uma atividade mais ampla, que pretende servir a clientes previamente identificados como aprendizes e que possui objetivos de aprendizagem.

- educação informal: verdadeiro processo realizado ao longo da vida em que cada indivíduo adquire atitudes, valores, procedimentos e conhecimentos da experiência cotidiana e das influências educativas de seu meio - na família, no trabalho, no lazer e nas diversas mídias de massa. (Combs, Prosser e Ahmed, 1973 apud Marandino, 2008, p. 13).

Para Gohn (1999), a educação não-formal é discutida através de um contexto de educação bem mais amplo, se associando ao conceito de cultura e configurando um processo com várias dimensões, como "capacitação dos indivíduos para o trabalho, por meio de aprendizagem de habilidades; aprendizagem e exercício de práticas que habilitam os indivíduos a se organizarem com objetivos voltados para a solução de problemas coletivos; aprendizagem dos conteúdos da escolarização formal, em formas e espaços diferenciados; e educação desenvolvida na e pela mídia, em especial a eletrônica” (Gonh, 1999 apud Marandino, 2008, p. 14).

A autora destaca os vários espaços nos quais se desenvolvem as atividades de educação não-formal, tais como as associações de bairro, os sindicatos, as organizações não-governamentais, os espaços culturais e as próprias escolas. Para ela, entretanto, a educação não-formal não contempla experiências vivenciadas na família, no convívio com amigos, nos clubes, nos teatros, na leitura de jornais, nos livros, etc., sendo estas categorizadas como educação informal, já que possuem caráter espontâneo e permanente

No campo da aprendizagem, Falk \& Dierking (2002) criaram a expressão free-choice learning como forma de enfrentar a confusão entre os termos formal, não-formal e informal. Para eles, a 'aprendizagem por livre escolha' é todo tipo de aprendizagem que pode ocorrer fora da escola, especialmente em museus, centros de ciências, organizações comunitárias e nas mídias impressa e eletrônica 
1 Notas do curso 'A Pesquisa na Divulgação Científica', ministrada no VII ENPEC, Encontro Nacional de Pesquisa em Ensino de Ciências, Florianópolis, SC, 2009. Adaptado de Nascimento \& Ventura (2009). (incluindo a Internet). $\mathrm{Na}$ aprendizagem por livre escolha, o próprio indivíduo busca o conhecimento, devido a interesses próprios e não por imposição da escola. Segundo os autores, o que faz a aprendizagem diferente, neste caso, é principalmente o espaço físico, e inclusive o contexto social e a motivação do aprendiz.

Verifica-se que, geralmente, essas definições partem de parâmetros relativos ao local onde acontece a aprendizagem. Nesse sentido, Jacobucci (2008) sugere uma definição simplificada para espaços formais e não-formais de educação da seguinte forma:

De forma sintética, pode-se dizer que os espaços formais de Educação referem-se a Instituições Educacionais, enquanto que os espaços não-formais relacionam-se com Instituições cuja função básica não é a Educação formal e com lugares não-institucionalizados (Jacobucci, 2008, p. 57).

Desse modo, Instituições Educacionais (sejam elas maternais, pré-escolas, escolas e colégios, que abrangem toda a educação básica, e ainda as faculdades, universidades e quaisquer instituições de ensino superior) seriam os espaços onde ocorre a educação formal. Os espaços não-formais, por sua vez, seriam todos os outros lugares onde pudesse ocorrer algum tipo de aprendizagem. Se tal lugar for uma instituição não educacional regulamentada, que possua equipe técnica especializada, como, por exemplo, museus, parques ecológicos, zoológicos, jardins botânicos, planetários, institutos de pesquisa ou indústrias, pode-se considerar que ali ocorre a educação não-formal. Se o local, no entanto, for um espaço não institucionalizado, isto é, caracterizado por ambientes naturais ou urbanos que não dispõem de estruturação institucional, mas onde ainda seja possível a presença de práticas educativas, como ruas, praças, casas, parques, praias, campo de futebol, teatro, cinema, dentre outros inúmeros espaços, então seria ali um local passível da ocorrência de educação informal.

De forma sintética, Nascimento \& Ventura (2009) apresentam uma tentativa de caracterizar esses três espaços a partir de sete parâmetros, conforme apresentado no Quadro 1 $^{1}$ :

Quadro 1 - Características dos diferentes espaços de aprendizagem

\begin{tabular}{|c|c|c|c|}
\hline \multirow[t]{2}{*}{ Parâmetros } & \multicolumn{3}{|c|}{ Ambientes de Aprendizagem } \\
\hline & Formal & Não-Formal & Informal \\
\hline Intenção educativa & Sim & Sim & Às vezes \\
\hline Currículo & Sim, expresso & Talvez & Talvez \\
\hline Avaliação & $\begin{array}{l}\text { Sim (do } \\
\text { sujeito) }\end{array}$ & $\begin{array}{c}\text { Sim (da } \\
\text { atividade) }\end{array}$ & $\begin{array}{l}\text { Sim (do } \\
\text { suporte) }\end{array}$ \\
\hline Certificação & Sim & Talvez & Não \\
\hline $\begin{array}{c}\text { Tempo de } \\
\text { Aprendizagem }\end{array}$ & Definido & Indefinido & Indefinido \\
\hline $\begin{array}{c}\text { Percurso de } \\
\text { Aprendizagem }\end{array}$ & $\begin{array}{l}\text { Seqüencial } \\
\text { normativo }\end{array}$ & Narrativo & Narrativo \\
\hline Pro & Dinloma & $\mathrm{Obr}$ & $\mathrm{Vi}$ \\
\hline
\end{tabular}


2 Transição gradual de um contexto para outro, sem mudanças abruptas.
Assim, percebe-se que a educação que ocorre em espaços não-formais se diferencia das demais, concernindo às atividades educativas que ocorrem fora do sistema escolar, e que sejam intencionais por parte de todos os envolvidos. Tais atividades apresentam currículo e percurso de aprendizagem por meio de um roteiro, uma vez tratar-se de atividades organizadas e estruturadas, porém não institucionalizadas, destinadas a um público que, não sendo necessariamente o escolar, pode ou não possuir certificação e submete-se a um tempo de aprendizagem indefinido.

Marandino (2008), a partir de propostas de outros autores, acredita ser interessante que esses diferentes contextos educacionais sejam vistos como um continuum $^{2}$ e não como categorias estanques. Segundo ela, um museu, por exemplo, pode ser nomeado como um espaço de educação não-formal quando pensado como instituição estruturada, com intenção de aprendizagem e currículo. Mas tanto poderia ser considerado espaço de educação formal, durante uma visita escolar com intenção de aprendizagem de algum conteúdo dado em sala de aula, como poderia ser um local de educação informal, ao se pensar em uma visita pública, onde o visitante procura o museu para se divertir em um final de semana com amigos ou familiares, não tendo, nesse caso, nenhuma intenção de aprendizagem, conforme esquematizado pela figura 2.

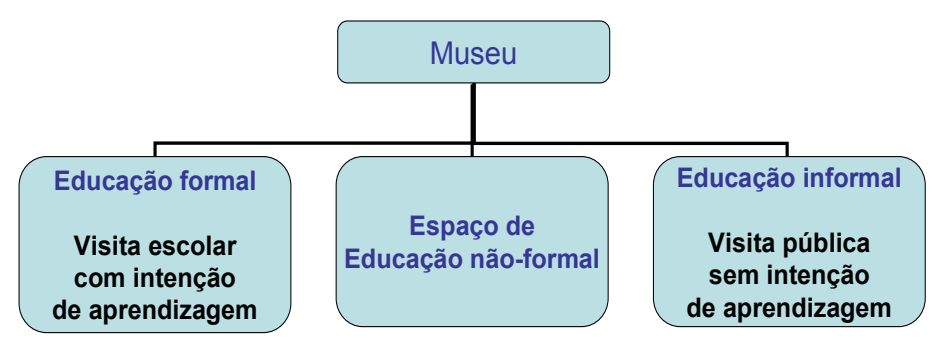

Figura 2 - Contextos educacionais aplicados em um museu

Todo este trabalho para tentar buscar melhores definições para esses contextos educacionais é justificado pelo fato de que espaços não-formais vêm, ultimamente, ganhando bastante importância entre os pesquisadores, devido ao seu poder de gerar interesse nos alunos. Para aprender, o aluno deve se sentir motivado; e, nesse sentido, os espaços não-formais de educação possuem exatamente esta função, posto que uma atividade não-formal pode despertar um maior interesse no aluno ao "suprir, ao menos em parte, algumas das carências da escola como a falta de laboratórios, recursos audiovisuais, entre outros, conhecidos por estimular o aprendizado" (Vieira et al., 2005, p.21).

Além disso, segundo Coutinho-Silva et al. (2005), a utilização de espaços não-formais no ensino proporciona vantagens para todos os envolvidos: alunos e professores enriquecem os conteúdos desenvolvidos em sala de aula; 
os visitantes melhoram sua percepção da ciência, sobretudo diante de conceitos espontâneos que traziam antes; os graduandos - que na maioria das vezes são os monitores desses espaços -, além de receberem uma grande gama de conteúdo teórico-experimental, vivenciam um processo de ensino-aprendizagem que se dá de forma dinâmica e lúdica; e os próprios pesquisadores, que têm a oportunidade de se aproximar das necessidades e problemas prementes da sociedade e de divulgar conceitos e resultados de suas pesquisas ao cidadão comum.

Por tudo que se vê, têm sido cada vez mais comuns as pesquisas no campo da educação não-formal, sobretudo naquele da educação em museus. Segundo Marandino (2006), alguns temas em especial têm se tornado alvo dos pesquisadores da área, como a utilização de referenciais da educação levados para o contexto não-formal, formação de profissionais no campo da educação em museus e pesquisas sobre o público que visita esses locais - ora na perspectiva de levantar seus interesses, impressões, conhecimentos, ora para avaliar a efetividade das ações do ponto de vista de seu lazer e aprendizagem -, bem como discussões acerca da definição da expressão 'educação não-formal' e sua relação com a chamada 'divulgação científica', tema que trataremos com maior ênfase a seguir.

\section{DIVULGAÇÃO CIENTÍFICA}

Conforme já foi destacado, assim como vêm crescendo as pesquisas na área da educação não-formal, também vêm se firmando as investigações sobre divulgação científica.

À semelhança da discussão a respeito dos conceitos de educação formal, não-formal e informal, que são controversos, alguns conceitos usados em pesquisas sobre divulgação científica demandam novas percepções e compreensões. Destacaremos duas indagações que consideramos fundamentais por sinalizarem a abrangência dos termos: divulgar e ensinar são sinônimos? São complementares?

Analisando alguns estudos sobre este campo, verificou-se que muitos autores afirmavam ser importante perceber que há uma diferença entre 'ensinar ciências' e 'divulgar ciências'. No entanto, conforme observa Marandino et al. (2004), não existe um consenso relativo à definição dos termos divulgar e ensinar. Ao mesmo tempo em que se encontram afirmações sobre a função social de ambas as práticas que as aproximam como complementares, é possível também identificar posições que as afastem, atribuindo à divulgação o papel motivador como instrumento pedagógico sem, contudo, substituir o aprendizado sistemático.

Outra discussão está em diferenciar 'divulgação' de outros termos como 'disseminação', 'generalização', 'propagação', 'publicação', 'multiplicação', 'difusão', 'vulgarização', 'popularização' e 'alfabetização científica', que muitas 
vezes são considerados sinônimos em dicionários, tendo o sentido de ampliar o domínio, tornar público, estender a todos a ciência. Tais termos aparecem para o tratamento da informação em diferentes esferas de produção, acerca, por exemplo, de como a ciência é tratada em diferentes meios, seja no acadêmico, nos eventos científicos, nos museus de ciência ou, ainda, nos livros, nas revistas e em outros meios de comunicação em massa.

Na literatura da área, os autores apresentam algumas diferenças entre esses conceitos, mas não há um consenso entre eles. No entanto, conforme aponta Ribeiro (2007), os termos 'multiplicação', 'generalização' e 'propagação' são pouco utilizados por estudiosos da área, enquanto os termos 'vulgarização', 'popularização' e 'divulgação' são mais próximos. Já o termo 'vulgarização' é pouco utilizado no Brasil, mas bastante comum na França, enquanto o termo 'popularização' é utilizado com freqüência por autores da língua inglesa. No Brasil, o termo 'divulgação científica' é o mais fortemente aplicado.

Na mesma pesquisa, Ribeiro (2007) cita Antonio Pasquali (apud Bueno, 1988), que diferencia os outros termos de acordo com a linguagem a quem se destina. Assim, ‘disseminação' seria empregado quando a ciência é transmitida com uma linguagem especializada a um grupo restrito a especialistas, sendo dessa maneira mais rebuscada; 'divulgação', quando a linguagem rebuscada é transformada em linguagem acessível ao grande público; e o termo ‘difusão' seria utilizado quando a ciência é transmitida com uma linguagem universalmente compreensível a todos.

Para Bueno (1984), a divulgação científica ocorre em dois níveis: o que envolve os cientistas e seus pares (disseminação científica) ou o que pretende alcançar um público maior (divulgação). Conforme Bossler (2009), muitas vezes a divulgação científica carrega os estigmas de 'inexata' e 'não confiável', e, portanto, fadada ao desprezo pela comunidade científica, exatamente por causa dessa 'informalidade', revelada na medida em que se destina a um público, em geral, leigo no assunto. Encontra-se aí a relação entre divulgação científica e educação não-formal.

A divulgação científica, contudo, pode acontecer na escola ou fora dela. Poderíamos então, da mesma forma que discriminamos educação formal, não-formal e informal, qualificar a divulgação científica como formal, não-formal e informal. Nesse sentido, poderíamos considerar um professor que leva textos de revistas especializadas para trabalhar com os alunos em sala de aula como um caso de divulgação científica formal, os professores que levam seus alunos para participar de eventos científicos, ou visitar um museu de ciências, como entes da divulgação científica não-formal, ou um programa de televisão, ou de rádio, que aborda temas científicos como elemento de divulgação científica informal.

Sendo assim, vamos considerar que a divulgação cien- 
tífica formal aproxima-se mais do conceito de disseminação, alfabetização científica ou, ainda, de ensino, por valer-se de uma linguagem formal restrita a um público escolar; que a divulgação científica não-formal é o mais próximo do que Pasquali considera como a divulgação científica propriamente dita, por utilizar uma linguagem acessível a um grande público; e que a divulgação científica informal identifica-se à difusão ou à popularização científica, por apresentar-se em linguagem informal universalmente compreendida por todos. Esta relação está esquematizada na figura 3.

Neste artigo, adotaremos os termos 'ensino', 'divulgação' e 'popularização' por serem os mais utilizados no Brasil, e pelo fato deste estudo tratar dos âmbitos da educação formal, não-formal e informal.

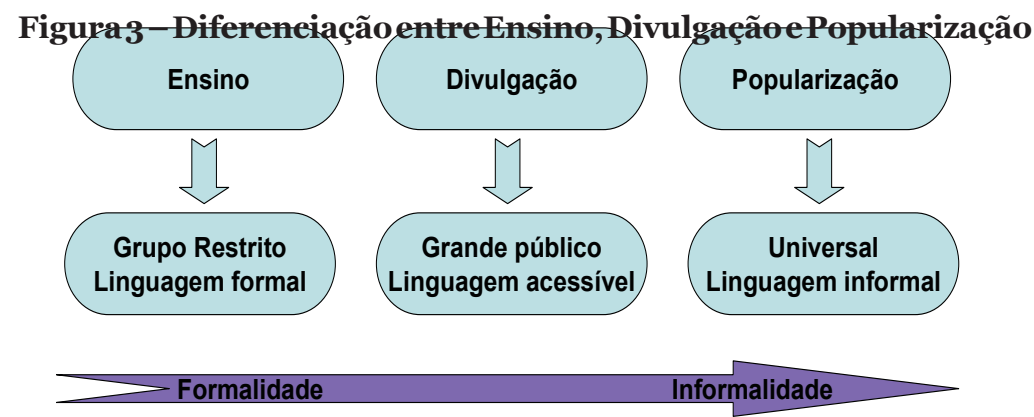

De acordo com Nascimento \& Ventura (2009), a denominação 'divulgação científica' é dada a toda a prática de difusão da cultura científica e tecnológica fora dos círculos dos especialistas e dos quadros formais de ensino, mostrando a íntima relação entre divulgação e educação não-formal.

Dentro de uma perspectiva atual, a educação não-formal deve completar o papel da escola cada vez que essa falta à sua missão de divulgação e de apropriação por todos da cultura científica e tecnológica (Nascimento \& Ventura, 2009, p.4).

Gostaríamos de enfatizar que esta escolha tem apenas o objetivo de impor os limites da pesquisa. Além de controversos, conforme exposto anteriormente, tais conceitos variam de acordo com a tradição de pesquisa e não têm limites bem definidos, visto que o sujeito transita em situações que se complementam resultando no processo educativo.

\section{VISITAS ESCOLARES}

Quando a professora chega à sala de aula e diz: $\mathrm{Va}$ mos realizar uma excursão ao zoológico?, os alunos logo comemoram: Oba! Vamos passear!.

Provavelmente, todos nós já devemos ter passado por isso alguma vez em nossa trajetória escolar. Saídas da escola representam momentos de lazer para os alunos. Constantemente, vemos os professores promovendo 'ex- 
cursões' com seus alunos, em zoológicos, museus, grutas, indústrias e diversos outros locais. Os alunos, por sua vez, adoram participar de tais atividades.

Visitas escolares são comumente referidas por excursões ou passeios. Existem outros termos, mais técnicos, tais como 'turismo pedagógico', 'saída de campo', 'visita técnica', 'estudo do meio' ou 'viagem de estudos'. Evitaremos aqui utilizar todas essas denominações, sobretudo os termos 'excursão', 'passeio', 'turismo' e 'viagem', que frequentemente nos remetem a saídas de lazer e não de estudo. Sabemos, porém, que todos estes termos são utilizados no dia a dia escolar, sem distinção, já que, de certa forma, para os alunos (e para alguns professores) uma visita escolar não deixa de ser um momento de lazer. No presente caso, adotaremos o termo 'visita escolar', porque ele preenche os aspectos da mudança de ambiente e do caráter pedagógico e reflexivo veiculado propriamente pela escola.

Procurando por pesquisas acadêmicas sobre o tema, não encontramos nenhuma que definisse esse termo. Recorrendo ao dicionário, a definição de 'visita', segundo Houaiss (2001), é ir ver, rever ou conhecer algo ou alguém com determinada finalidade. Assim, pressupõe-se que as visitas escolares sejam também utilizadas pelos professores com alguma determinada finalidade. Podemos, então, definir 'visita escolar' como um recurso didático utilizado pelos professores para organizar uma atividade curricular intencionalmente planejada, servindo para desenvolver e complementar conteúdos curriculares, mediante saídas direcionadas para ambientes externos ao espaço físico da escola ou da sala de aula. São, portanto, atividades educativas de cunho pedagógico, e não necessariamente contidas no plano de curso.

Celestin Freinet (1975), educador francês que desenvolveu uma pedagogia bastante utilizada no mundo todo, criou o termo 'aula-passeio', que denota uma aula de campo voltada para o interesse do aluno, posto que, diante da oportunidade de sair de sala, o aluno passeia e tem aula, ao mesmo tempo. Freinet acreditava que o interesse da criança não estava na escola, e sim no que acontecia fora dela. Nesse sentido, idealizava essa atividade com o objetivo de trazer motivação, ação e vida para a escola, o que representaria uma forma de somar educação e lazer, aprendizagem e diversão.

Os Parâmetros Curriculares Nacionais (PCN) também dão grande importância e estimulo à prática de visitas escolares.

Além de gratificante, é altamente instrutivo para professor e alunos o trabalho que envolva saídas da sala de aula ou mesmo da escola para visitar um museu, ir a uma exposição de fotografias ou de obras de arte, conhecer um 
sítio arqueológico, etc. Estes momentos são geralmente lúdicos e representam oportunidades especiais para que todos se coloquem diante de situações diferentes, em atividades especiais de acesso a outros tipos de informação e de envolvimento com as vivências sociais mais amplas da sociedade e do conhecimento humano. As visitas aos locais são recursos didáticos favoráveis ao envolvimento dos alunos em situações de estudo, estimulando interesse e participação (Brasil, 1998, p. 90).

Ainda, de acordo com os PCN,

$\mathrm{O}$ estudo do meio envolve uma metodologia de pesquisa e de organização de novos conhecimentos, que requer atividades anteriores à visita, levantamento de questões a serem investigadas, seleção de informações, observação de campo, confrontação entre os dados levantados e os conhecimentos já organizados por pesquisadores, interpretação, organização de dados e conclusões. Possibilita o reconhecimento da interdisciplinaridade e de que a apreensão do conhecimento histórico ocorre na relação que estabelece com outros conhecimentos físicos, biológicos, geográficos, artísticos (Brasil, 1998, p. 93).

Assim, utilizar a visita como prática de interdisciplinaridade, de forma a integrar diversas áreas do conhecimento, é uma sugestão de metodologia de trabalho que pode ser considerada pelo professor. Além disso, os PCN sugere que o professor visite o local com antecedência, procurando se informar sobre o espaço e sobre as potencialidades da visita, e que crie atividades anteriores e posteriores à saída, explorando atividades de pesquisa relacionadas à visita com diferentes abordagens e com objetivo de complementar as aulas.

O professor, aliás, é a peça chave no que se refere às visitas escolares. É ele quem planeja e decide o que deve ser trabalhado antes, durante e após a visita. Ao propor saídas escolares de campo, os professores devem observar inúmeras questões, que vão desde o planejamento, incluindo custo, transporte, horário, local a ser visitado e preparação prévia, até as atividades posteriores à visita. Portanto, se quisermos compreender como os espaços não-formais de educação estão sendo utilizados pela comunidade escolar, precisamos entender como os professores percebem estes espaços, o que eles pensam e o que esperam quando realizam tais visitas.

Vimos que a utilização dos espaços não-formais para complementar as aulas tem se tornado freqüente através das pesquisas. Sobre a importância da utilização de espaços não-formais como ambientes educativos, Marandino (2001) aponta os principais motivos que levam os professores a visitarem os museus de ciências. Entre eles, estão a oportunidade de vivenciar situações que, por falta de ma- 
3 Banco de Teses e Dissertações Sobre Educação em Astronomia, disponível na página eletrônica: <http://www.dme.ufscar.br/btdea/ inicio >. (Acesso em: 25 abr. 2011). terial e espaço físico, não podem ser reproduzidas em sala e a abordagem pedagógica de forma mais interdisciplinar, dando ênfase à experiência prática da teoria exposta em aula, além do contato com fontes atualizadas do conhecimento científico e da ampliação cultural.

\section{EDUCAÇÃO EM ASTRONOMIA}

Nosso quarto tema, no qual vamos inserir os outros três anteriores, é o tema da educação em Astronomia. Esta área, relativamente bastante recente no Brasil, apresentou um grande desenvolvimento na última década. Segundo Bretones \& Megid Neto (2005) e Langhi (2008), que realizaram levantamentos de teses e dissertações defendidas no Brasil, neste campo de estudo, o primeiro trabalho encontrado data de 1973. Até 2010, estes levantamentos ${ }^{3}$ contabilizavam 68 pesquisas acadêmicas. O gráfico da figura 4 apresenta a distribuição anual destes trabalhos, mostrando a evolução ocorrida nos últimos anos.

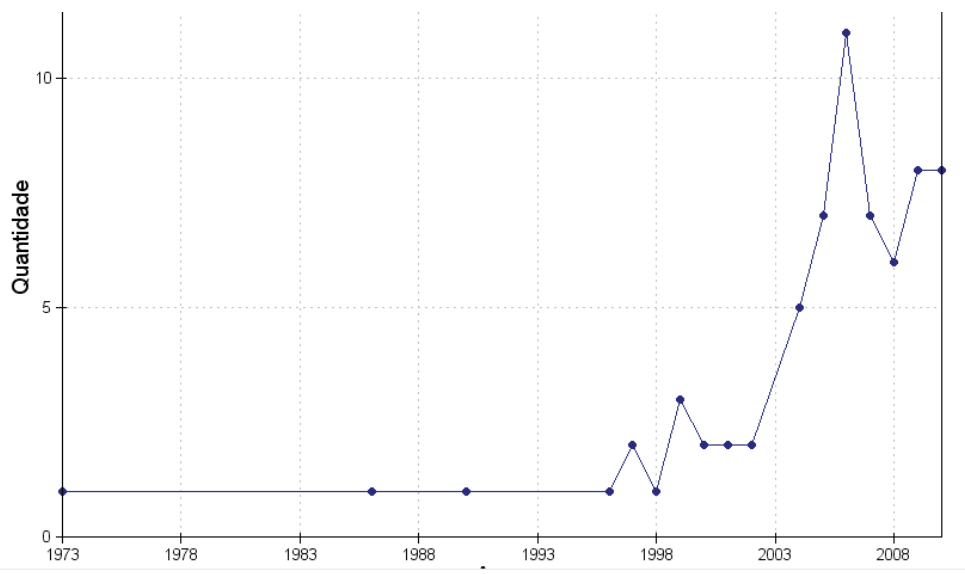

Figura 4 - Gráfico da distribuição anual de teses e dissertações em educação em Astronomia no Brasil. (Fonte: Disponível em: <http://www.dme.ufscar.br/ btdea/estatisticas $>$. Acesso em: 25 abr. 2011)

Estes resultados indicam que a educação em Astronomia tem se destacado como uma área em desenvolvimento no país, apesar de ainda ser restrito a um pequeno grupo de pesquisadores. O mesmo é observado no âmbito internacional.

Segundo estados da arte no campo da educação em Astronomia, produzidos por Wall (1973), Bishop (1977), Bailey \& Slater (2004), Bretones, Megid Neto \& Canalle (2006) e Bretones \& Megid Neto (2011), dentre os temas investigados ganham destaque programas de divulgação e popularização da Astronomia para o público geral através da educação não-formal e informal; discussões curriculares da Astronomia; desenvolvimento de materiais e instrumentos de ensino; dificuldades no processo de ensino-aprendizagem e compreensão de estudantes e professores; e a educação continuada em Astronomia voltada para professores da educação básica.

OS CONTEXTOS EDUCACIONAIS APLICA- 


\section{DOS À EDUCAÇÃO EM ASTRONOMIA}

Podemos considerar, no caso da educação em Astronomia, que ela pode ocorrer na escola, nos espaços não-formais, como observatórios astronômicos, planetários e museus de astronomia, ou ainda através de diferentes meios de comunicação, como Internet, televisão, cinema, revistas e conversas em geral. Dessa maneira, acordaremos falar, num primeiro momento, em educação formal, não-formal e informal da Astronomia, dependendo do local onde ela ocorre.

Indo mais a fundo, percebemos que cada um desses processos educativos se relaciona também com a sua intenção. Assim, o ensino de Astronomia formal é intencional, enquanto o ensino de Astronomia informal não é intencional. Já o ensino de Astronomia não-formal pode ou não ser intencional, de acordo com o objetivo. Portanto, notamos que, conforme já foi discutido, devemos considerar esses três conceitos como um continuum, de modo que uma visita a um observatório astronômico ou um planetário, pode tanto ter a intenção de ensinar a Astronomia, aproximando-se da educação formal, como pode ter a intenção apenas de entreter através da popularização da Astronomia, aproximando-se mais de uma educação informal. Nesse sentido, poderíamos relacionar aqui os conceitos de ensino, divulgação e popularização científica discutidos anteriormente, conforme a figura 5 .

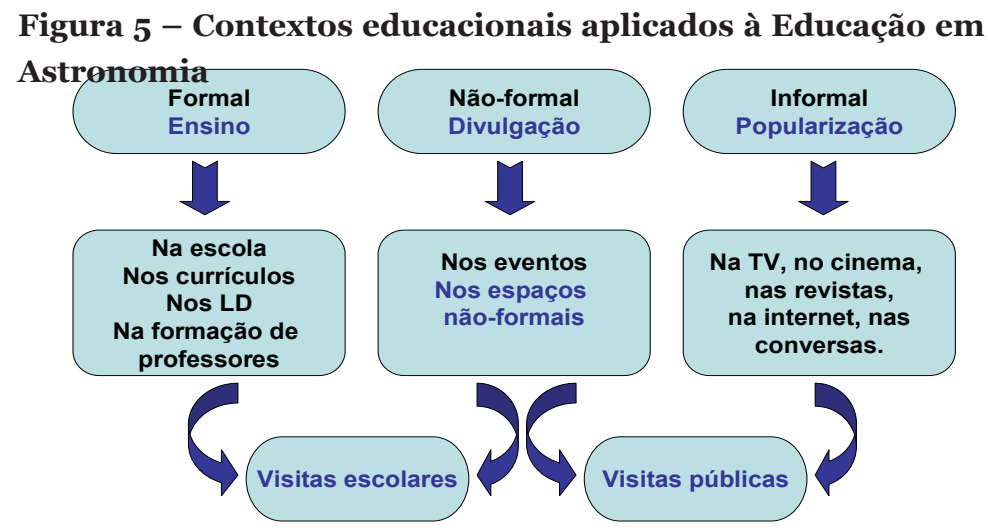

Se intenção da visita a um observatório ou planetário é inserir a Astronomia no currículo, ou ilustrar a aula dada em sala, o espaço é visto como uma extensão da sala de aula, similar a um laboratório escolar. O processo educativo que ocorre ali é o ensino de Astronomia, valendo-se de uma linguagem mais formal, destinada a um grupo de alunos. A visita, nesse caso, pode inclusive fazer parte de um projeto desenvolvido na escola, que será avaliado.

No entanto, poderia haver uma visita cuja intenção fosse fazer com que os alunos conhecessem um espaço de Astronomia, sem necessariamente haver ali um processo de ensino formal, aproximando-se mais de uma divulga- 
ção científica. Ou ainda, poderíamos conceber uma visita não-escolar, aonde o público vai para se divertir, assistir a uma apresentação de cúpula ou observar pelo telescópio, não apresentando intenção de aprender Astronomia. Isso é o que chamamos na figura 5 de visita pública, e seria um processo de popularização da ciência. Por tal, um observatório astronômico, ou um planetário, pode ser considerado um espaço de ensino, divulgação ou popularização da Astronomia, respectivamente conforme o tipo de visita e a intencionalidade, ou o objetivo, a que se destina.

Podemos, então, esquematizar o que foi apresentado conforme mostrado na figura 6 .

Figura 6 - Esquema exemplificando o continuum dos contextos educacionais aplicados à Educação em Astronomia

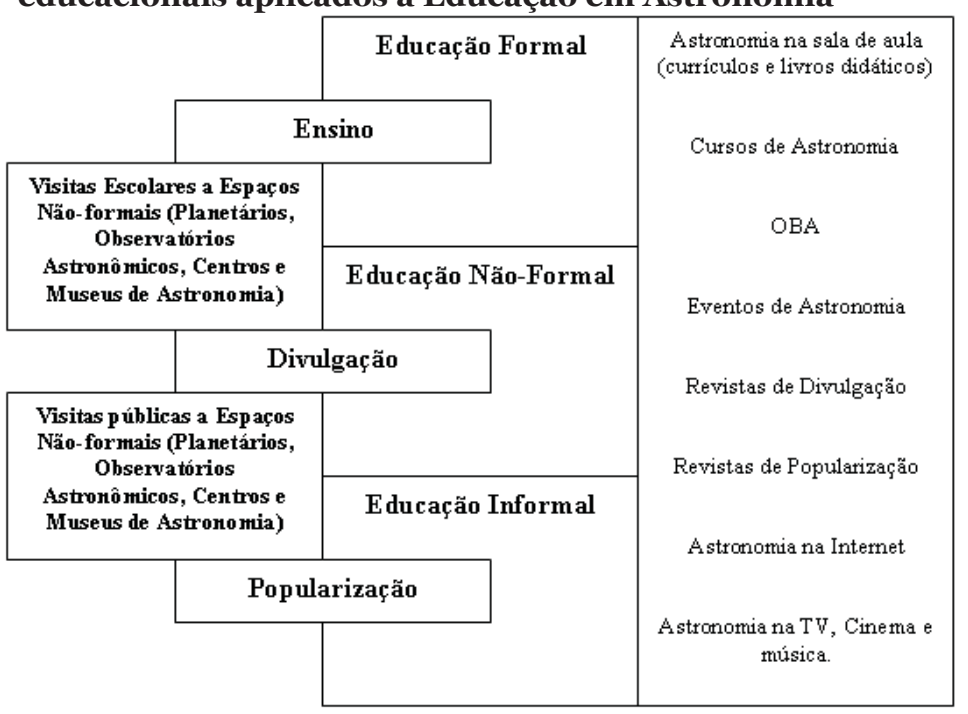

\section{O OBJETIVO DA VISITA ESCOLAR AO OB- SERVATÓRIO ASTRONÔMICO SEGUNDO OS PROFESSORES}

Para investigar os objetivos que levam professores a realizar visitas escolares a um espaço de educação não-formal, em especial, a um observatório astronômico, e desta forma, perceber como eles concebem e utilizam este espaço, realizamos entrevistas semi-estruturadas com um grupo de dez professores que visitam regularmente tal espaço. A definição desse grupo de professores foi realizada a partir do perfil traçado por meio de informações colhidas em cerca de 27 mil fichas de visitantes, registradas pelo observatório no período de 1997 a 2009. Esse grupo se mostrou heterogêneo no que se refere à idade, formação e experiência profissional, mas bastante homogêneo considerando sua relação com a Astronomia, com educação não-formal e com a visita ao espaço. Todos demonstraram, inclusive, possuir claros objetivos diretos, detectados a partir da análise dos discursos, conforme proposta por Orlandi (1996).

Nesta pesquisa, utilizamos a definição de objetivo 
dada por Houaiss (2001), segundo o qual, objetivo 'é aquilo que se pretende alcançar quando se realiza uma ação; um alvo, uma finalidade, um intuito ou um propósito'. O objetivo direto vem a ser a causa formal apresentada à escola para a realização da visita.

Entre as causas formais apresentadas pelos sujeitos, oito disseram que o objetivo da visita era a participação em um projeto que desenvolviam na escola. Para quatro deles, contudo, esse projeto era a participação na Olimpíada Brasileira de Astronomia (OBA). A OBA é um evento anual aberto à participação de escolas públicas ou privadas, urbanas ou rurais. Trata-se de uma competição voluntária entre alunos, desde o primeiro ano do ensino fundamental até o último ano do ensino médio, que ocorre totalmente dentro da própria escola, sendo assim uma maneira de divulgar Astronomia no âmbito da educação formal. Os outros dois sujeitos apresentaram, como causa formal, a inserção da Astronomia em suas aulas de Física. Sendo assim, optamos por fazer a distinção das causas formais em três categorias, conforme apresentado no quadro 2.

Quadro 2 - Grupos de professores e categorias de causas formais

\begin{tabular}{|c|c|c|}
\hline Grupo & $\begin{array}{c}\text { Número de } \\
\text { professores }\end{array}$ & Causa formal \\
\hline I & 4 & Participação em Projeto \\
\hline II & 4 & Participação na OBA \\
\hline III & 2 & Inserção da Astronomia no currículo \\
\hline
\end{tabular}

Destacamos, assim, três grupos de professores que possuíam a mesma causa formal; dentro de cada grupo, eles se mostraram ainda mais homogêneos, apresentando mesmos propósitos e utilizando o espaço do Observatório com funções semelhantes.

Assim, os professores do Grupo I tinham o objetivo de realizar a visita ao Observatório a fim de cumprir um projeto no qual estavam envolvidos em suas respectivas escolas, e consideravam aquele espaço como um local propício para corresponder aos objetivos almejados pelo projeto. Todos mostraram possuir interesse em participar de atividades não-formais e projetos, como era de se esperar. Dentro desse grupo, no entanto, dois professores concebiam o observatório astronômico como um espaço de ensino e divulgação da Astronomia, pois seus projetos estavam relacionados especificamente a questões astronômicas. Já para os outros dois, que possuíam projetos relacionados ao tema Ciência e Tecnologia, o espaço não seria utilizado em sua função de oferecer Astronomia aos alunos e, sim, por seu potencial em oferecer Ciência de um modo geral, não tendo a visita qualquer relação com conteúdos de Astronomia desenvolvidos em sala de aula.

Os professores do Grupo II, que possuíam o objetivo principal de realizar a visita ao Observatório para garantir a participação dos alunos na Olimpíada Brasileira de Astro- 
nomia, mostraram conceber aquela visita como facilitador da aprendizagem e como forma de atender os interesses dos alunos. Em face da competição, traziam o propósito de motivá-los e prepará-los, sendo o Observatório Astronômico, com a função de ensinar Astronomia, o local apropriado para esse fim. Nesse caso, as visitas em geral não faziam parte do planejamento do professor, tampouco da escola, indicando que, para tal grupo, a visita tem lugar mais em decorrência do interesse do aluno, que pede, do que do interesse dos professores ou de eventual imposição da escola.

O Grupo III, por sua vez, é o que possui mais características em comum. Ambos os professores lecionam Física para o ensino médio e incluem assuntos de Astronomia dentro dos conteúdos da disciplina, sendo a visita ao observatório uma atividade curricular que já consta no planejamento anual de suas aulas. O observatório astronômico assume, para eles, a função de espaço complementar à sala de aula, caracterizando o local onde os alunos vão relacionar teoria e prática da mesma forma que em um laboratório escolar. Interessante notar, neste caso, que a visita não objetiva a divulgação ou popularização da Astronomia, mas diretamente seu ensino, em conjunto com a Física.

Percebemos assim, que, para esse conjunto de dez professores, o observatório astronômico tem a função de espaço de ensino ou divulgação de Astronomia, sendo que para oito é um espaço onde ocorre ensino (educação formal) de Astronomia, ou de Ciências em geral, e para apenas dois é um espaço onde ocorre divulgação (educação não-formal) de Astronomia.

\section{CONSIDERAÇÕES FINAIS}

Os resultados deste trabalho indicam algumas reflexões que podem auxiliar nas discussões futuras sobre educação não-formal, sobretudo no tocante à educação em Astronomia no Brasil.

Uma delas se refere à classificação de um espaço como sendo de educação formal e não-formal e o processo educativo que ocorre nestes locais. Percebemos que não existe consenso para definir estes contextos educacionais, visto que tais conceitos variam de acordo com a tradição de pesquisa e não têm limites bem definidos, pois o sujeito transita em situações que se complementam resultando no processo educativo. Assim, esses diferentes contextos educacionais devem ser vistos como um continuum e não como categorias estanques. Ou seja, um espaço como o observatório astronômico em questão, classificado como espaço de educação não-formal é o local onde muitos professores levam seus alunos através de visitas escolares, para lá eles terem a educação formal de Astronomia, já que esta não ocorre dentro da escola.

Investigar o que professores buscam através de idas 
a um observatório astronômico com seus alunos pode contribuir para revelar em que espaços como esse precisam mudar para atender aos objetivos da comunidade escolar. Por exemplo, poderiam criar programações específicas para atender cada objetivo. Uma visita que visa a participação dos alunos na OBA, poderia, assim, caracterizar-se por palestras, oficinas e observações específicas visando uma preparação para aquele público, que irá participar de uma competição afinal. Para aqueles professores que procurarão o observatório no intuito de complementar a aula de Física dada em sala, as atividades oferecidas poderiam estar em consonância com a matéria dada, através de palestras e laboratórios interativos sobre temas gerais - sem, é claro, perder a função própria de um observatório em oferecer Astronomia à população. Intenções como estas poderiam ser conhecidas através das fichas de inscrição, onde o professor responsável pela visita indicasse qual é o objetivo principal da visita.

No que diz respeito às visitas escolares de um modo geral, foi possível entender como os professores utilizam o espaço não-formal de educação, de acordo com seus objetivos e propósitos, e propor assim uma definição formal do conceito de 'visita escolar', que até então era inexistente, mesmo em pesquisas anteriores. Propomos, por vez, a seguinte definição: visita escolar é um recurso didático utilizado pelos professores para programar uma atividade curricular intencionalmente planejada, servindo para desenvolver e complementar conteúdos curriculares, mediante saídas direcionadas para ambientes externos ao espaço físico da escola ou da sala de aula. São, portanto, atividades educativas de cunho pedagógico, e não necessariamente contidas no plano de curso.

Estamos cientes de que os resultados apresentados sejam referentes a um pequeno grupo de professores que, com seus alunos, realizam visitas regulares ao local, não havendo possibilidade de maiores generalizações. No entanto, inferimos que outros professores que visitem estes e outros espaços de educação não-formal, e que possuam objetivos semelhantes, possam conceber e utilizá-los da mesma forma, o que justifica o caráter ainda extensivo de nossa investigação.

Sendo assim, consideramos relevantes e de extrema importância a discussão proposta por este artigo, assim como os resultados apontados nesta pesquisa, que responderam questões que nos instigavam, forneceram contribuições notáveis e que, por outro lado, provocaram a revelação de novas questões e abordagens para outras pesquisas, posteriores. 
BAILEY, J. M.; SLATER, T. F. A Review of Astronomy Education Research. Astronomy Education Review, 2 (2), 2003. p. 20-45. Disponível em: <http://www.phys.lsu.edu/ classes/fall2009/phys8000/Review_Astronomy_Ed_Research.pdf.> Acesso em: 15 Jul. 2011.

BISHOP, J. E. United States Astronomy Education: Past, Present, and Future, Science Education, 61, 295. 1977.

BOSSLER, A. P. A ciência pode ser divertida: a emoção na mediação do conhecimento científico. Tese de Doutorado. Faculdade de Educação. UFMG. Belo Horizonte, 2009.

BRASIL. Secretaria de Educação Média e Tecnologia. Parâmetros Curriculares Nacionais: $\mathrm{PCN}$ de $5^{\mathrm{a}}$ a $8^{\mathrm{a}}$ série. Brasília. MEC/SEMTEC. 1998. Disponível em <http://portal.mec.gov.br/index.php?option=com_conte nt\&view=article\&id=12657\%3Aparametros-curriculares-nacionais-50-a-80-series\&catid=195\%3Aseb-educacao-basica\&Itemid=859> . Acesso em: 10 de janeiro de 2011.

BRETONES, P.S.; MEGID NETO, J. Tendências de Teses e Dissertações sobre Educação em Astronomia no Brasil. Boletim da Sociedade Astronômica Brasileira, v. 24, n. 2, p. 35-43, 2005.

BRETONES, P. S., MEGID NETO, J., CANALLE, J. B. G. A Educação em Astronomia nos trabalhos das reuniões anuais da Sociedade Astronômica Brasileira. Boletim da Sociedade Astronômica Brasileira, 26, 55. 2006

BRETONES, P.S.; MEGID NETO, J. An Analysis of Papers on Astronomy Education in Proceedings of IAU Meetings from 1988 to 2006 . Astronomy Education Review, 10 (1), 2011. Disponível em:

$<$ http://aer.aas.org/resource/1/aerscz/v10/i1/p010102_s1>. Acesso em: 15 Jul. 2011.

BUENO, W. C. Jornalismo Científico no Brasil: aspectos teóricos e práticos. Em: Série Pesquisa - Comunicação Jornalística e Editorial, n. 7. 1988.

BUENO, W. C. Jornalismo científico no Brasil: os compromissos de uma prática dependente. 1984, $364 \mathrm{f}$. Tese (Doutorado) - USP, ECA, São Paulo, 1984.

CAZELLI, Sibele. Divulgação Científica em Espaços Não-Formais. In: XXIV Congresso da Sociedade de Zoológicos do Brasil, 2000, Belo Horizonte. Anais do XXIV Congresso da Sociedade de Zoológicos do Brasil, 2000.

COUTINHO-SILVA, R. et al. Interação museu de ciên- 
cias-universidade: contribuições para o ensino não-formal de ciências. Cienc. Cult., São Paulo, v.57, n. 4, 2005. Disponível em:

$<$ http://cienciaecultura.bvs.br/scielo.php?pid=S000967252005000400 015\&script=sci_arttext $>$. Acesso em: 15 Jul. 2011.

FALK, J.; DIERKING, L.D. Lessons Without Limit: how free-choice learning is transforming education. California: Altamira Press, 2002.

FREINET, C. As técnicas Freinet da Escola Moderna. Lisboa: Editora Estampa, 1975.

GOHN, M.G. Educação Não-Formal e Cultura Política: impactos sobre o associativismo do terceiro setor. São Paulo: Cortez, 1999.

HOUAISS, A.; VILLAR, M. S. Dicionário Houaiss de Língua Portuguesa. Rio de Janeiro: Editora Objetiva, 2001.

JACOBUCCI, D. F. C. Contribuições dos Espaços Não-formais de Educação para a Formação da Cultura Científica. Em Extensão (Uberlândia), v. 7, p. 55-66, 2008.

LANGHI, R.. Resumo de teses e dissertações nacionais sobre educação em astronomia. Bauru: UNESP/ Observatório Didático Astronômico "Lionel José Andriatto”, 2008. 15 p. Disponível em:

$<$ http://unesp.br/astronomia/mostra_arq_multi.php?arquivo=4793>. Acesso em: 15 Jul. 2011.

LINHARES, F. R. C. O objetivo das visitas escolares a um observatório astronômico na visão dos professores. 2011. 239p. Dissertação (Mestrado em Educação). Faculdade de Educação, Universidade Federal de Minas Gerais, Belo Horizonte, Minas Gerais.

MARANDINO, M. Interfaces na Relação Museu-Escola. Caderno Catarinense de Ensino de Física, Florianópolis, v. 8, n. 1, 2001, p. 85-100.

MARANDINO, M. et al. A Educação Não Formal e a Divulgação Científica: o que pensa quem faz? In: IV Encontro Nacional de Pesquisa em Ensino de Ciências ENPEC, 2004, Bauru. Atas do IV Encontro Nacional de Pesquisa em Ensino de Ciências - ENPEC, 2004.

MARANDINO, M. Perspectivas da pesquisa educacional em museus de ciências. In: SANTOS, Flávia Maria Teixeira dos; GRECA, Ileana Maria (Orgs.). A pesquisa em ensino de ciências no Brasil e suas metodologias. Ijuí: Editora UNIJUÍ, 2006. p. 89-122. 
MARANDINO, M. (org.). Educação em museus: a mediação em foco. São Paulo: FEUSP, 2008.

NASCIMENTO, S. S., VENTURA, P. C. S. A Ciência e Tecnologia em Espaços Não Escolares: questões e definições. In: XI Reunión de la Red POP y el V taller de Ciencia, Comunicación y Sociedad, Montevideo, 2009.

ORLANDI, E. P. A linguagem e seu funcionamento: as formas do discurso. $4^{\circ}$ ed. São Paulo: Pontes, 1996.

RIBEIRO, R. A. Divulgação científica e ensino de Física: intenções, funções e vertentes. Dissertação de Mestrado. Instituto de Física, Instituto de Química, Instituto de Biociências e Faculdade de Educação. USP. São Paulo. 2007

VIEIRA, V.; BIANCONI, M. L; DIAS, M. Espaços não-formais de ensino e o currículo de ciências. Cienc. Cult., São Paulo, v. 57, n. 4, 2005. Disponível em: $<$ http://cienciaecultura.bvs.br/scielo.php?script=sci_ arttext\&pid=So009-67252005000400014\&lng $=$ en\&nrm $=$ iso $>$. Acesso em: 15 Jul. 2011.

WALL, C. A. A Review of Research Related to Astronomy Education. School Science and Mathematics, 73, 653. 1973 . 